\title{
Eosinophilic esophagitis: Clinical features, endoscopic findings and response to treatment
}

\author{
Robert Enns MD¹, Pooya Kazemi MD², Wiley Chung MD², Mitchell Lee MD²
}

\begin{abstract}
R Enns, P Kazemi, W Chung, M Lee. Eosinophilic esophagitis: Clinical features, endoscopic findings and response to treatment. Can J Gastroenterol 2010;24(9):547-551.
\end{abstract}

Eosinophilic esophagitis (EE) is a motility disorder of the esophagus that typically presents with dysphagia. The objective of the present study was to explore patient characteristics, clinical and endoscopic features, and response to treatment of patients with EE. Patients were selected retrospectively based on a review of biopsy results from previous endoscopies performed between 2004 and 2008. A total of 54 patients (41 men and 13 women) with biopsy-proven EE were included in the study. Further information regarding the patients' clinical and endoscopic features, and response to treatment were obtained through chart reviews and patient telephone interviews. The mean age of the patients at symptom onset was 30 years. All patients complained of dysphagia, $81 \%$ had a history of bolus obstruction, $43 \%$ had a history of asthma and $70 \%$ had a history of environmental allergies. Thirtythree per cent had a family history of asthma, while $52 \%$ had a family history of food or seasonal allergies. The most common endoscopic findings were rings and/or corrugations, which were found in $63 \%$ of patients. Swallowed fluticasone therapy resulted in symptom resolution in $74 \%$ of patients; however, $79 \%$ of these patients relapsed after discontinuing fluticasone therapy and required repeat treatments. Esophageal dilation was complication free and resulted in improvement in $80 \%$ of patients. However, $83 \%$ of those reporting improvement relapsed within one year. The clinical and endoscopic findings were similar to those found in the literature, with most patients requiring ongoing, repeated therapies. Further studies are needed to assess the safety and efficacy of treatment modalities ideally suited to patients with EE.

Key Words: Dysphagia; Endoscopy; Eosinophilic esophagitis; Esophageal food impaction; Esophagus

Cosinophilic esophagitis (EE) is an inflammatory disorder of - 1 the esophagus characterized by eosinophilic infiltration of the esophageal mucosa (1). Recent studies (2-4) have reported the prevalence of the disease to be between $0.5 \%$ and $1.1 \%$ and increasing, and predominantly affecting males.

EE most commonly affects young men in their third to fourth decade of life (5). The most common symptoms include solid food dysphagia and food impaction, which occur in virtually all patients with the disorder (6-8). Heartburn and acid regurgitation are also common complaints in approximately $20 \%$ of patients $(9,10)$, with other symptoms including abdominal pain, chest pain and weight loss occurring less frequently (5).

Common endoscopic findings include esophageal rings, linear furrows and mucosal fragility (11). Recent North American

\section{L'œsophagite à éosinophiles : Les caractéristiques cliniques, les observations endoscopiques et la réponse au traitement}

L'œsophagite à éosinophiles (OÉ) est un trouble de la motilité de l'œesophage qui s'accompagne généralement d'une dysphagie. La présente étude visait à explorer les particularités, les caractéristiques cliniques et endoscopiques et la réponse clinique des patients au traitement de l'OÉ. Les patients ont fait l'objet d'une sélection rétrospective d'après une analyse des résultats des biopsies d'endoscopies effectuées entre 2004 et 2008. Au total, 54 patients ( 41 hommes et 13 femmes) ayant une OÉ démontrée par biopsie ont participé à l'étude. Les autres renseignements relatifs aux caractéristiques cliniques et endoscopiques des patients et à leur réponse au traitement ont été tirés de l'examen de leur dossier et d'entrevues téléphoniques. À l'apparition des symptômes, les patients avaient un âge moyen de 30 ans. Tous se sont plaints de dysphagie, $81 \%$ avaient des antécédents d'obstruction du bolus, $43 \%$, des antécédents d'asthme, et $70 \%$, des antécédents d'allergies environnementales. Trentetrois pour cent avaient des antécédents familiaux d'asthme, et $52 \%$, des antécédents familiaux d'allergies alimentaires ou saisonnières. Les principales observations endoscopiques étaient les anneaux ou les corrugations, constatées chez $63 \%$ des patients. Une thérapie par ingestion de fluticasone a assuré la résolution des symptômes chez $74 \%$ patients, mais $79 \%$ d'entre eux ont essuyé une rechute après l'arrêt du traitement et ont dû subir plusieurs traitements. La dilatation de l'œesophage ne s'associait à aucune complication et a amélioré l'état de $80 \%$ des patients. Cependant, $83 \%$ de ceux qui avaient déclaré une amélioration ont fait une rechute dans l'année. Les observations cliniques et endoscopiques étaient similaires à celles obtenues dans les publications, la plupart des patients ayant besoin de thérapies continues et répétées. D'autres études s'imposent pour évaluer l'innocuité et l'efficacité des modalités thérapeutiques les mieux adaptées aux patients ayant une OÉ.

${ }^{1}$ Department of Medicine, Division of Gastroenterology; ${ }^{2}$ Faculty of Medicine, University of British Columbia, Vancouver, British Columbia Correspondence: Dr Robert Enns, Department of Gastroenterology, St Paul's Hospital, University of British Columbia, 770-1190 Hornby Street,

Vancouver, British Columbia V5Z 1M9. Telephone 604-688-6332 ext 222, fax 604-689-2004, e-mail renns@interchange.ubc.ca

Received for publication November 17, 2009. Accepted January 19, 2010. 


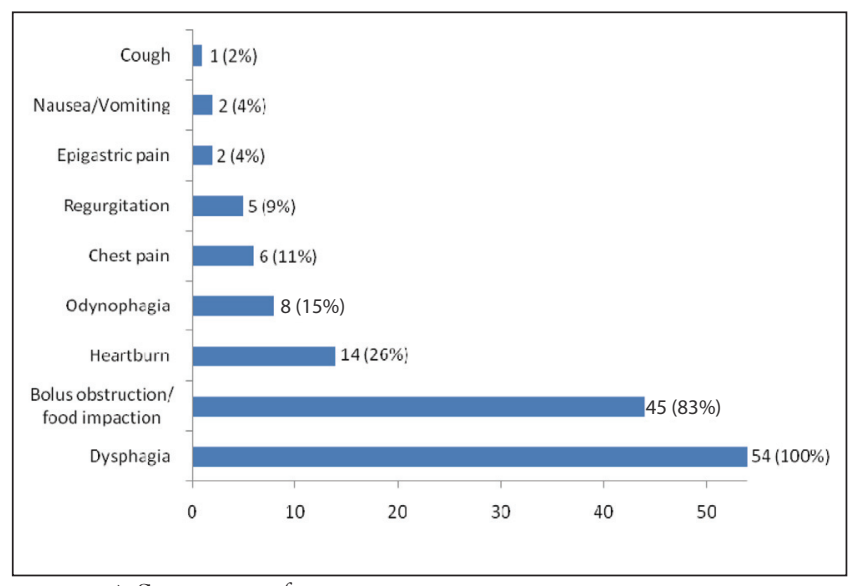

Figure 1) Summary of symptoms

high, esophageal dilation has been used; however, it is associated with the potential risk of complications such as mucosal tears and perforations (15).

The purpose of the present study was twofold: to analyze patient characteristics, clinical features and endoscopic findings in a cohort of patients diagnosed with EE at St Paul's Hospital, a tertiary care referral centre in Vancouver, British Columbia; and to assess the response to treatment in this group of patients.

\section{Patients}

\section{METHODS}

Patients in the present study were retrospectively selected based on a review of biopsy results from previous endoscopies performed at St Paul's Hospital. All patients with biopsyproven $\mathrm{EE}$, defined as more than 20 eosinophils/HPF, were included in the study. Further information regarding the patients' clinical features at the time of diagnosis, response to treatment, endoscopic findings and follow-up data were obtained retrospectively through chart reviews and patient telephone interviews.

\section{Esophagogastroduodenoscopy}

All patients had their esophagogastroduodenoscopies performed at a single centre (St Paul's Hospital) by an experienced team of gastroenterologists. During the endoscopy procedures, findings were recorded in patient charts. Representative samples were taken and sent to the department of pathology for histological analysis. The endoscopic findings of the current study were based on gross observations at the time of endoscopy.

\section{Histology}

All biopsies were reviewed by an experienced team of pathologists in the laboratory department of St Paul's Hospital. Histological diagnosis of $\mathrm{EE}$ was defined as the presence of more than 20 eosinophils/HPF discovered on biopsies taken at endoscopy.

\section{RESULTS}

A total of 54 patients (41 men, 13 women) met the inclusion criteria for the present study. The mean $( \pm$ SD) age of the patients was $43.5 \pm 14$ years (range 18 to 77 years). The mean age at which patients first developed symptoms was much younger ( 30 years, range eight to 73 years).

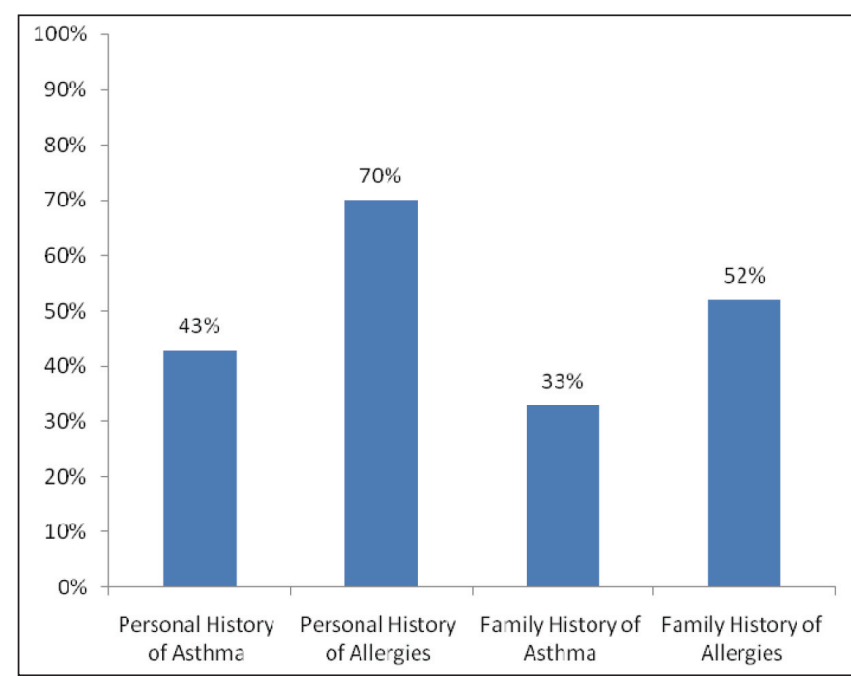

Figure 2) Summary of atopic conditions

\section{Presenting symptoms}

Patient symptoms are summarized in Figure 1. All patients (100\%) reported dysphagia at the time of diagnosis. The second most common symptom was bolus obstruction in 45 patients (83\%). Heartburn was reported by 14 patients (26\%). Twenty-two patients (41\%) reported having to present to the emergency department on at least one occasion with either severe dysphagia or food impaction. Of these patients, 13 (59\%) required endoscopic removal of food items.

Patients' personal and family history of atopic conditions were analyzed, the results of which are summarized in Figure 2. Of the 46 patients whose asthma and allergy history was available, $20(43 \%)$ reported a history of asthma and 32 (70\%) reported either food, seasonal or drug allergies. Blood work results for 29 patients was available and, of these, eight patients (28\%) had peripheral eosinophilia (defined as a count of $0.5 \times 10^{9} / \mathrm{L}$ or greater). Nineteen patients were seen by an allergist after being diagnosed with EE - 12 of these patients (63\%) had positive skin allergy tests. The patients' family history of atopic conditions was also considered. Atopic condition history was available for 42 patients and, of these, 14 (33\%) had a family history of asthma, while $22(52 \%)$ had a family history of food, drug or seasonal allergies.

\section{Endoscopic findings}

Endoscopic reports were also reviewed to determine the common endoscopic findings in EE (Figure 3). Thirty-four patients (63\%) had rings (Figure 4) or corrugation, 10 (19\%) had whitish exudates and papules or plaques, and eight patients (15\%) had linear furrows. Less common findings were strictures in three patients, narrowing in two patients and mucosal friability in two patients. A normal-looking esophagus was noted in seven $(13 \%)$ patients.

\section{Treatment}

Both medical and endoscopic management of $\mathrm{EE}$ were used in the present population. A total of 40 (74\%) patients were treated with swallowed fluticasone $250 \mu \mathrm{g}$. Patients were advised to start with a trial of four puffs swallowed twice daily for six weeks. Five of these patients were lost to follow-up. Of the 35 patients with available follow-up data, 26 patients (74\%) reported improvement 


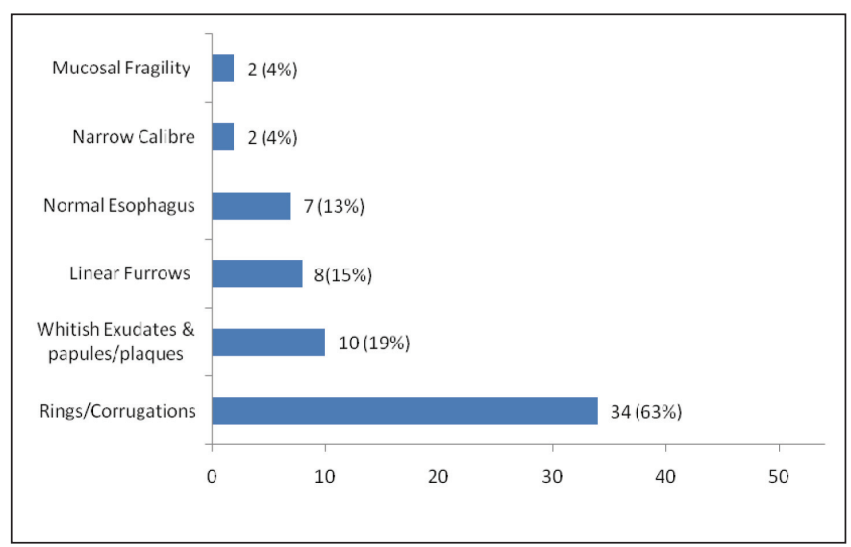

Figure 3) Summary of endoscopic findings

or complete resolution of their symptoms after the six-week trial. Further follow-up data were available for 24 of these patients. Of these, 19 (79\%) reported relapse of their symptoms requiring them to restart fluticasone or seek further therapy. Eleven patients had been treated with proton pump inhibitors (PPIs) at some point before starting fluticasone. One of these patients reported having had mild improvement of their dysphagia symptoms while on PPI therapy; the other 10 patients reported no benefit.

During the study period, a total of 15 patients underwent at least one endoscopic dilation at the centre. The response to treatment was measured by subjective improvement. There were no dilation-associated complications. Twelve patients (80\%) reported improvement in their symptoms. However, 10 of these patients (83\%) reported relapse of their symptoms within one year after dilation.

\section{DISCUSSION}

EE is an inflammatory disorder of the esophagus that is being increasingly diagnosed in the adult population. In the present study, we assessed the patient characteristics, clinical features, endoscopic findings and response to treatment of a cohort of patients from a tertiary Canadian medical centre.

The mean age at which our patients had developed their first symptoms was 30 years, while the mean age at diagnosis was older than 40 years. The reasons for the delayed diagnosis are unclear, but may be due to the mild nature of EE. There were many more men than women ( $76 \%$ versus $24 \%)$. These results closely resemble those found in the literature. The belief that patients with $\mathrm{EE}$ tend to be young men who are diagnosed in their third to fourth decade of life was consistent with the results of the present study. Why EE is more common in men remains to be elucidated.

Similar to the symptoms reported in the literature, the predominant symptoms of our patients were dysphagia (100\%) and bolus food impaction (81\%). Because dysphagia in a young patient is a well-accepted indication for endoscopy, selection bias in the present population may have occurred; however, many of the patients had other symptoms as well. Patients could present with more than one symptom (eg, heartburn) and some had other complaints as outlined in Figure 1. These other symptoms were also considered to be legitimate reasons to perform a biopsy at the time of endoscopy. Dysphagia symptoms were so severe in some of our patients that $41 \%$ had at least one visit to

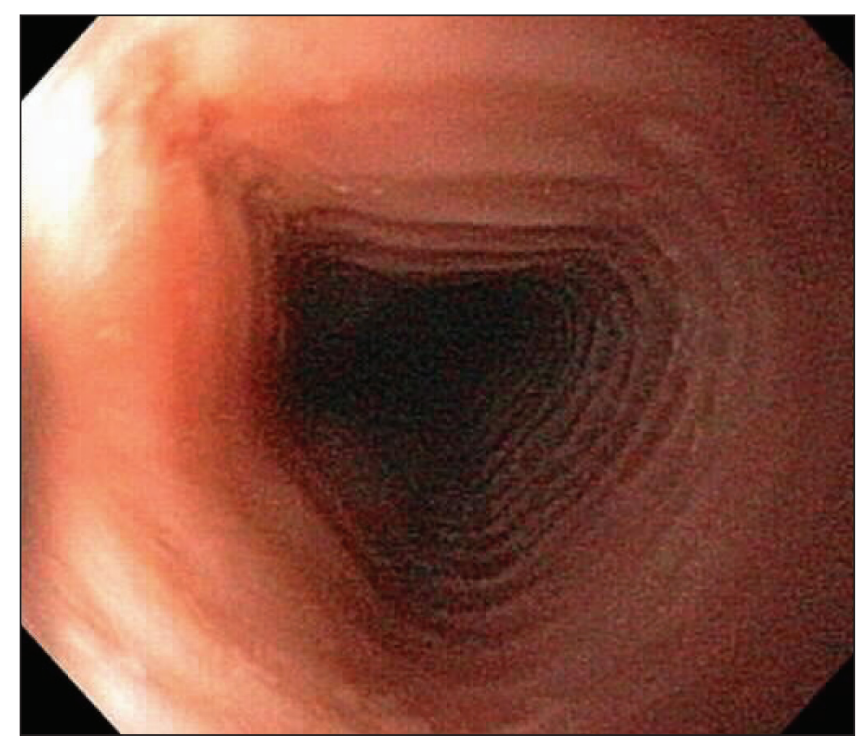

Figure 4) A ringed esophagus

the emergency department (ED) for either severe dysphagia or bolus food impaction. A previous prospective study (16) demonstrated that more than $50 \%$ of patients presenting to the $\mathrm{ED}$ for food impaction had histological evidence of EE (16). EE should be considered in all patients presenting to the ED with bolus food impaction. Heartburn was the distant third most common symptom in our patients at $26 \%$. This finding is very similar to previous studies $(9,12)$, in which $23 \%$ of the pooled subjects reported gastroesophageal reflux disease symptoms. It is yet to be demonstrated whether gastroesophageal reflux disease and $\mathrm{EE}$ simply coexist in certain individuals or whether one condition contributes to or causes the other. Some authors (17) have gone as far as recommending that a clinical trial of PPI be tried in all patients suspected of having EE.

Many studies have demonstrated a strong clinical association of EE with asthma and other allergic conditions. One meta-analysis (9) reported the presence of allergic and/or atopic conditions in $55 \%$ of patients with EE. In our study, allergies and asthma were reported by $43 \%$ and $70 \%$ of patients, respectively. There was also a strong family history of allergies and asthma, at $32 \%$ and $52 \%$, respectively. In addition, $75 \%$ of the 19 patients who underwent a skin allergy evaluation tested positive. These results fit well with the hypothesis that $\mathrm{EE}$ is associated with a T-helper cell 2 type immune response, and that EE may be induced by aeroallergens as well as food allergens.

The most common endoscopic finding in our study was the presence of esophageal rings or corrugation (63\% of patients). A normal-looking esophagus was noted in $13 \%$ of our patients. One meta-analysis (9) reported a normal-looking esophagus in $9 \%$ of patients, while another (10) reported it in $17 \%$ of patients. These results emphasize the need to take biopsies even if the esophagus appears to be normal.

One of the limitations of the present study was that our patients were selected based on the histological definition of EE (ie, more than 20 eosinophils/HPF). Although various recommendations have been made regarding the histological definition of $\mathrm{EE}$, the diagnostic criterion for $\mathrm{EE}$ according to the current North American consensus statement (12) is a peak 
count of 15 eosinophils/HPF or more, in the proper clinical context. Therefore, our study may have underestimated the number of patients with $\mathrm{EE}$ who had presented to our centre by selecting only patients with more severe disease.

Both medical and endoscopic strategies were used to treat our cohort of patients. Swallowed fluticasone was moderately successful and resulted in complete or partial improvement in $69 \%$ of the patients who received it. However, there was a high relapse rate on discontinuation of the drug. PPI therapy was unsuccessful, with only one of 11 patients who received this therapeutic option reporting improvement. Other medical therapies such as systemic corticosteroids, leukotriene receptor antagonists, budesonide and biologics were not studied. Our experience with PPI mirrors other published reports (12), which point to this modality as being largely ineffective. Our results with fluticasone therapy are more disappointing than previously published results. For example, three prospective studies $(8,18,19)$, comprised of a total 70 patients, showed improvement or complete resolution of symptoms in all patients who were treated with fluticasone. However, the reported relapse rates on discontinuation of fluticasone were high - up to $91 \%$ in one study (20). Given the retrospective nature of our study, a detailed record of the patients' symptoms before starting treatment was not available. If we had administered a pretreatment questionnaire, similar to the studies mentioned above, we may have had slightly different results.

There remains a need for a randomized controlled trial to assess the efficacy of topical steroid therapy in adults with EE. The only randomized, double-blinded, placebo-controlled study with fluticasone was performed by Konikoff et al (21) in 36 children. This study reported clinical and histological improvement in 35 and 34 children, respectively.

In our study, dilation therapy was not associated with any complications and was more successful than swallowed fluticasone. Dilation therapy resulted in subjective improvement in $82 \%$ of the patients who received it. However, $86 \%$ of these patients had relapse of their symptoms within one year after treatment. Because of a significant relapse rate and its potential for complications, we do not advocate dilation as a primary first-line therapy. Several studies have demonstrated that dilation is safe and effective for the treatment of EE. Schoepfer et al (22) dilated 10 stenotic EE patients who were unresponsive to topical corticosteroids with bougienage. There were no major complications, and all 10 patients had symptomatic relief that was sustained after a mean follow up of six months. Croese et al (23) used esophageal dilation to treat strictures in 17 patients with EE, with all but one of the patients reporting symptomatic relief. There were no serious complications, but esophageal tears occurred during some of the dilations. Despite being reported safe in these studies, dilation is associated with potential risks for serious complications such as esophageal perforations. For example, Cohen et al (24) performed a retrospective study of endoscopic procedures in 36 patients. They found complications in 11 patients: seven had vertical mucosal lacerations, three had esophageal perforations and one experienced an emesisinduced rupture. Most groups agree that dilation should be reserved for those who have failed pharmacological treatment. Given the fragility of the esophageal mucosa in patients with $\mathrm{EE}$, it is important to perform dilations in a careful and gradual manner.
For individuals with difficult-to-control symptoms or with clear atopic issues, referral for allergy testing is suggested. Our results in adults have been only moderately successful; however, in the face of long-term or failing topical steroids and repeated dilations, clearly, all other options (particularly those demonstrated to be effective in larger studies, especially in children) should be considered.

\section{CONCLUSION}

EE is an inflammatory condition of the esophagus that occurs predominantly in young men. The most common symptoms are solid food dysphagia and food impaction. EE should be strongly considered in those who present to the ED with dysphagia and/or food impaction, particularly with a history of atopic disorders. The most common endoscopic finding in patients with EE is a ringed esophagus. Swallowed fluticasone is a safe and effective treatment; however, relapse rates are very high. Dilation therapy appears to be safe and effective, but high relapse rates combined with the potential risk of esophageal perforation make this therapeutic approach less attractive than medical therapy. In adults, there remains a need for a randomized controlled trial to assess the safety and efficacy of various treatment modalities.

AUTHOR CONTRIBUTIONS: Dr P Kazemi designed the study, performed the literature search, engaged in data collection and wrote parts of the manuscript. Dr R Enns wrote and edited the manuscript. Dr W Chung contributed to the study design and aided with data collection. Dr M Lee helped with data collection and wrote parts of the manuscript.

DISCLOSURE: The authors have no financial disclosures or conflicts of interest to declare.

\section{REFERENCES}

1. Eosinophilic esophagitis in adults: An emerging problem with unique esophageal features. Gastrointest Endosc 2004;59:355-61.

2. Kapel RC, Miller JK, Torres C, et al. Eosinophilic esophagitis: A prevalent disease in the United States that affects all age groups. Gastroenterology 2008;134;5:1316-21.

3. Straumann A, Simon HU. Eosinophilic esophagitis: Escalating epidemiology? J Allergy Clin Immunol 2005;115:418-9.

4. Prasad GA, Smyrk TC, Schleck C, et al. Secular trends in the epidemiology and outcomes of eosinophilic esophagitis in Olmsted County, Minnesota (1976-2007). Gastroenterology 2008;134:S1977. (Abst)

5. Prasad G, Talley NJ. Eosinophilic esophagitis in adults. Gastroenterol Clin North Am 2008;37:349-68.

6. Arora AS, Perrault J, Smyrk TC. Topical corticosteroid treatment of dysphagia due to eosinophilic esophagitis in adults. Mayo Clin Proc 2003;78:830-5.

7. Straumann A, Spichtin HP, Grize L, Bucher KA, Beglinger C, Simon HU. Natural history of primary eosinophilic esophagitis: A follow-up of 30 adult patients for up to 11.5 years. Gastroenterology 2003;125:1660-9.

8. Remedios M, Campbell C, Jones DM, et al. Eosinophilic esophagitis in adults: Clinical, endoscopic, histology findings, and response to treatment with fluticasone propionate. Gastrointest Endosc 2006;63:3-12.

9. Pasha SF, DiBaise JK, Kim HJ, et al. Patient characteristics, clinical, endoscopic, and histologic findings in adult eosinophilic esophagitis: A case series and systematic review of the medical literature. Dis Esophagus 2007;20:311-9.

10. Sgouros SN, Bergele C, Mantides A. Eosinophilic esophagitis in adults: A systematic review. Eur J Gastroenterol Hepatol 2006;18:211-7.

11. Fox VL. Eosinophilic esophagitis: Endoscopic findings. Gastrointest Endosc Clin N Am 2008;18:45-57. 
12. Furuta GT, Liacouras CA, Collins MH, et al. Eosinophilic esophagitis in children and adults: A systematic review and consensus recommendations for diagnosis and treatment. Gastroenterology 2007;133:1342-63.

13. Collins MH. Histopathologic features of eosinophilic esophagitis. Gastrointest Endosc Clin N Am 2008;18:59-71;viii-ix.

14. Blanchard C, Rothenberg ME. Basic pathogenesis of eosinophilic esophagitis. Gastrointest Endosc Clin N Am 2008;18:133-43.

15. Bohm M, Richter JE. Treatment of eosinophilic esophagitis: Overview, current limitations, and future direction. Am J Gastroenterol 2008;103:2635-44.

16. Prasad GA, Talley NJ, Romero Y, et al. Prevalence and predictive factors of eosinophilic esophagitis in patients presenting with dysphagia: A prospective study. Am J Gastroenterol 2007;102:2627-32.

17. Spechler SJ, Genta RM, Souza RF. Thoughts on the complex relationship between gastroesophageal reflux disease and eosinophilic esophagitis. Am J Gastroenterol 2007;102:1301-6.

18. Arora AS, Perrault J, Smyrk TC. Topical corticosteroid treatment of dysphagia due to eosinophilic esophagitis in adults. Mayo Clin Proc 2003; 78:830-5.
19. Lucendo AJ, Pascual-Turrión JM, Navarro M, et al. Endoscopic, bioptic, and manometric findings in eosinophilic esophagitis before and after steroid therapy: A case series. Endoscopy 2007;39:765-71.

20. Helou EF, Simonson J, Arora AS. 3-yr-follow-up of topical corticosteroid treatment for eosinophilic esophagitis in adults. Am J Gastroenterol 2008;103:2194-9.

21. Konikoff MR, Noel RJ, Blanchard C, et al. A randomized, double-blind, placebo-controlled trial of fluticasone propionate for pediatric eosinophilic esophagitis. Gastroenterology 2006;131:1381-91

22. Schoepfer AM, Gschossmann J, Scheurer U, Seibold F, Straumann A. Esophageal strictures in adult eosinophilic esophagitis: Dilation is an effective and safe alternative after failure of topical corticosteroids. Endoscopy 2008;40:161-4.

23. Croese J, Fairley SK, Masson JW, et al. Clinical and endoscopic features of eosinophilic esophagitis in adults. Gastrointest Endosc 2003;58:516-22.

24. Cohen MS, Kaufman AB, Palazzo JP, Nevin D, Dimarino AJ Jr, Cohen S. An audit of endoscopic complications in adult eosinophilic esophagitis. Clin Gastroenterol Hepatol 2007;5:1149-53. 


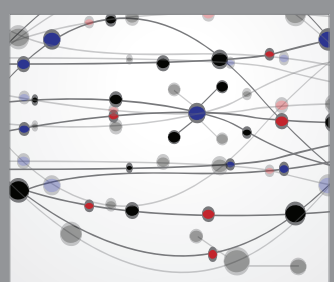

The Scientific World Journal
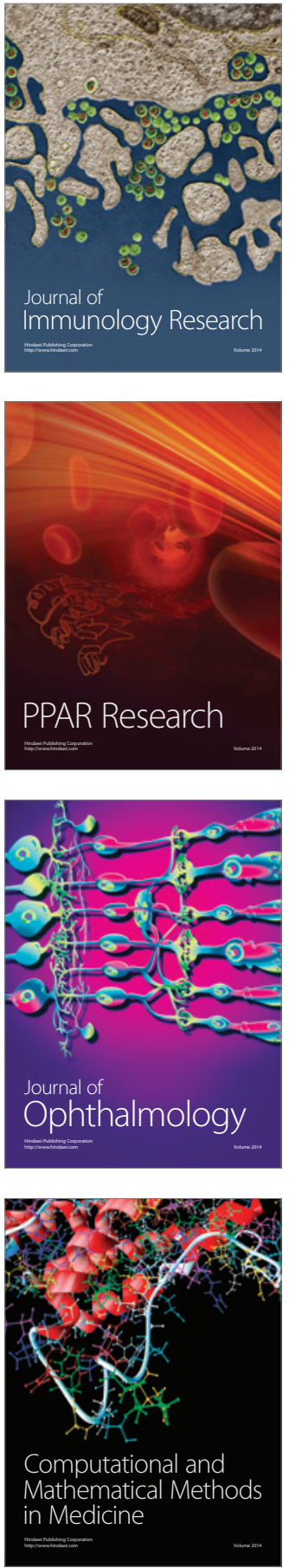

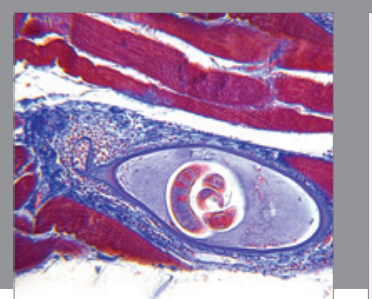

Gastroenterology Research and Practice

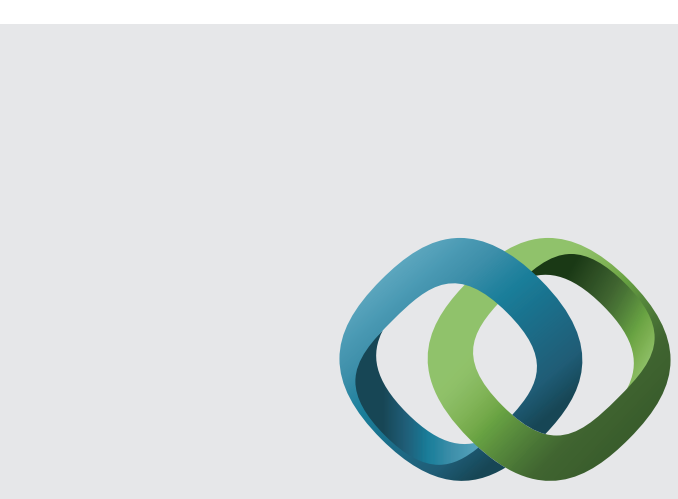

\section{Hindawi}

Submit your manuscripts at

http://www.hindawi.com
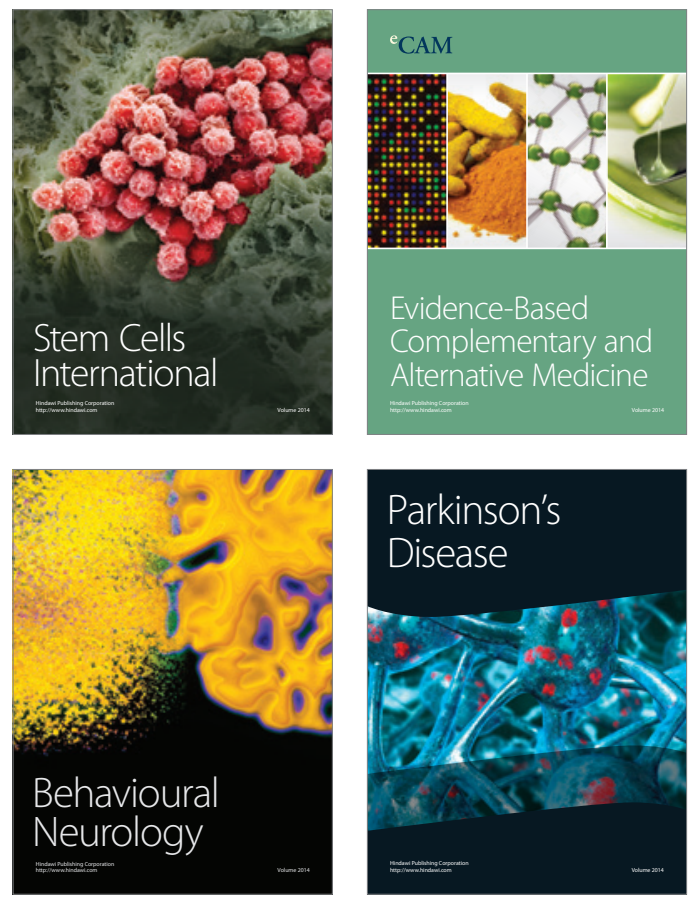
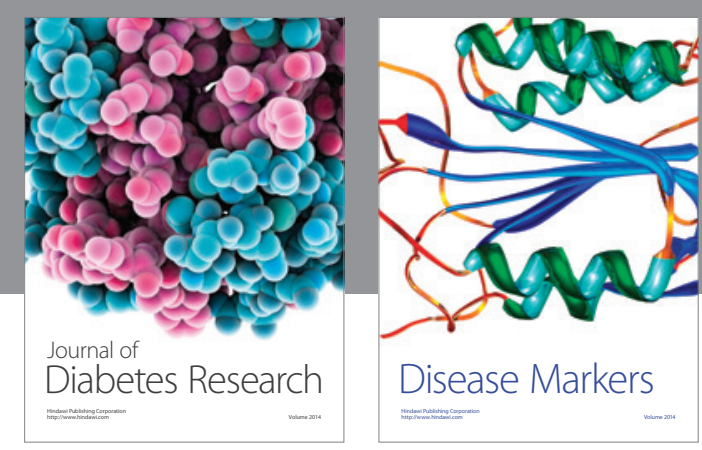

Disease Markers
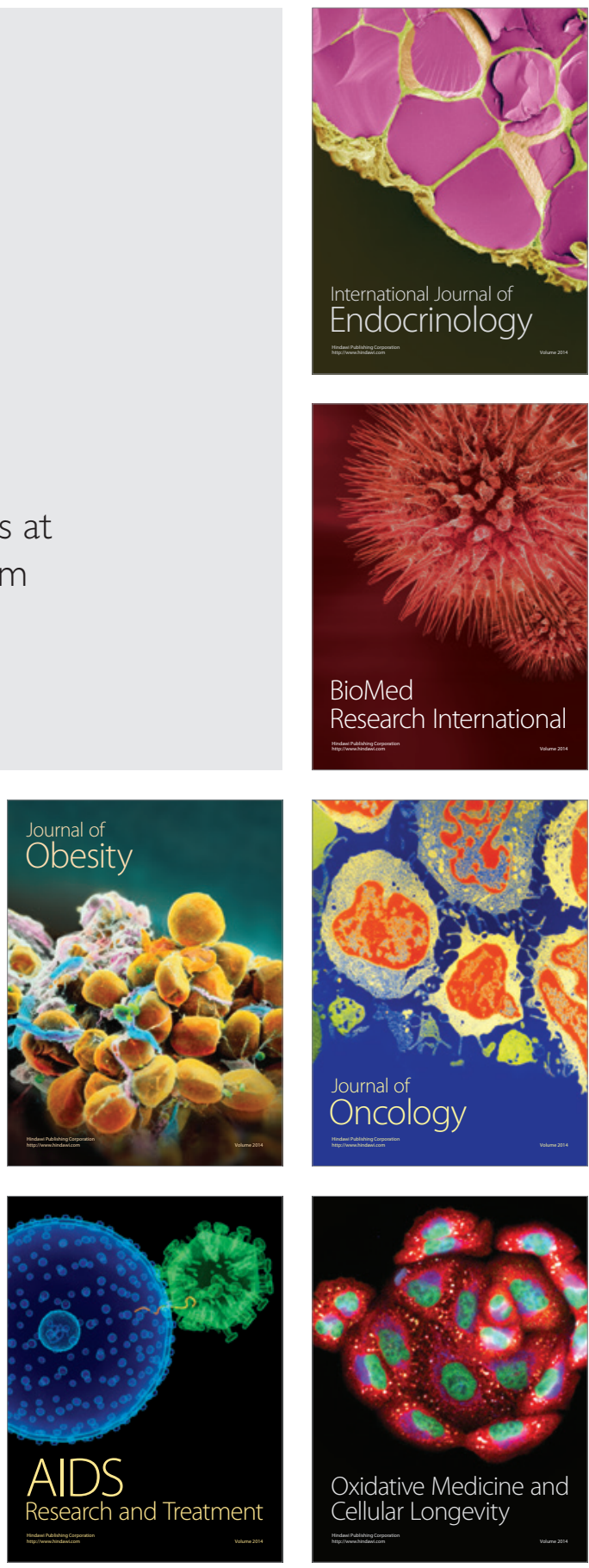